\title{
Valor nutritivo de dietas contendo torta de mamona submetida a métodos alternativos de destoxificação para ovinos
}

\author{
[Nutritive value of feeds containing castor bean cake subjected to alternative methods \\ of detoxification for sheep] \\ R.N. Furtado ${ }^{1}$, M.S.S. Carneiro ${ }^{2}$, M.J.D. Cândido ${ }^{2}$, F.H.T. Gomes ${ }^{1}$, E.S. Pereira ${ }^{2}$, \\ R.C.F.F. Pompeu ${ }^{3}$, W.A. Sombra ${ }^{4}$ \\ ${ }^{1}$ Aluno de pós-graduação - Universidade Federal do Ceará - Fortaleza, CE \\ ${ }^{2}$ Universidade Federal do Ceará - Fortaleza, CE \\ ${ }^{3}$ Embrapa Caprinos e Ovinos - Sobral, CE \\ ${ }^{4}$ Aluno de pós-graduação - Universidade Federal do Ceará - Fortaleza - Fortaleza, CE
}

\begin{abstract}
RESUMO
Avaliaram-se o consumo e a digestibilidade de nutrientes por ovinos alimentados com rações contendo torta de mamona sem tratamento (NT), tratadas com calcário calcítico (CC), ureia (UR), fosfato monobicálcico (FOS) e por autoclave (ACL). Foram utilizados 20 ovinos em delineamento em blocos ao acaso, sendo 10 machos inteiros e 10 fêmeas, mestiços de raça Morada Nova. As dietas foram isoproteicas e isoenergéticas. A ricina foi parcialmente desnaturada pelos tratamentos de destoxificação da torta de mamona. Não houve efeito dos tratamentos de destoxificação da torta de mamona sobre o consumo de nutrientes. A digestibilidade da fibra em detergente neutro no tratamento NT foi de 57,5\%, maior que no tratamento $\mathrm{CC}$, de $52,4 \%$. A digestibilidade do extrato etéreo foi mais alta no tratamento CC, média de $71,3 \%$, em relação ao tratamento FOS, de $68,2 \%$. Houve maior consumo de fibra em detergente neutro e fibra em detergente ácido dos machos em relação às fêmeas quando o consumo foi expresso em $\mathrm{g} / \mathrm{dia}$. A torta de mamona NT pode ser utilizada em dietas de ovinos como alimento proteico alternativo, participando em até $8 \%$ da dieta total, sem ocasionar redução expressiva no consumo e na digestibilidade.
\end{abstract}

Palavras-chave: ovino, biodiesel, digestibilidade, ricina, Ricinus communis, subproduto

\begin{abstract}
Feed intake and digestibility were evaluate in sheep fed diets containing castor bean cake with no treatment $(N T)$, treated with calcium carbonate $(C C)$, urea (UR), phosphate monodicalcium (FOS) and autoclave (ACL). We used 20 sheep in a randomized block design, being 10 males and 10 females, crossbred Morada Nova. The diets were isonitrogenous and isocaloric. Ricin was partially denatured through the treatments of detoxification of the castor bean cake. There was no treatment effect of detoxification of the castor bean cake on the intake of nutrients. The digestibility of neutral detergent fiber in the NT treatment had a 57.52\% average, higher than the CC treatment which had an average of $52.42 \%$. The digestibility of ether extract was higher in CC treatment, which had an average of $71.29 \%$ compared to the FOS treatment that had an average of $68.22 \%$. Regarding the effect of sex, there was a higher intake of neutral detergent fiber and acid detergent fiber in males compared to females when intake was expressed as g/day. The castor bean cake NT can be used in rations for sheep as an alternative protein source participating in up to $8 \%$ of the total ration, without causing significant reductions in intake and digestibility.
\end{abstract}

Keywords: sheep, biodiesel, digestibility, ricin, Ricinus communis, byproduct

Recebido em 3 de maio de 2011

Aceito em 9 de setembro de 2011

E-mail: rafaelnfurtado@yahoo.com.br 


\section{INTRODUÇÃO}

O atual cenário da matriz energética nacional vislumbra uma participação ascendente dos biocombustíveis na produção de energia. Dentre as espécies indicadas para a produção de biodiesel, a mamoneira destaca-se no Nordeste do Brasil, apresentando-se como alternativa de grande importância econômica e social pela capacidade de produzir em condições de baixa precipitação pluviométrica, além de apresentar um bom mercado consumidor, podendo ser consorciada com outras culturas, constituindo excelente opção para a agricultura familiar.

Diversos subprodutos agroindustriais, quando empregados de forma racional, podem contribuir para a redução do custo da aquisição de concentrados (Carvalho Junior et al., 2010). A torta de mamona é um subproduto proteico com $34 \%$ de proteína bruta (PB); $71,5 \%$ de nutrientes digestíveis totais (NDT); $93 \%$ de matéria orgânica (MO); $55 \%$ de fibra em detergente neutro (FDN); 44\% de fibra em detergente ácido (FDA); $27 \%$ de cutina; $8 \%$ de extrato etéreo (EE); $0,72 \%$ de cálcio e $0,84 \%$ de fósforo ( $\%$ MS) (Pompeu, 2009; Oliveira et al., 2010).

Apesar do potencial de utilização na alimentação de ruminantes, a torta de mamona tem sido utilizada preferencialmente como fertilizante orgânico por ser considerada tóxica na alimentação animal, reduzindo sua competitividade em relação aos subprodutos de outras oleaginosas. Das três toxinas presentes na semente de mamona, a ricina é a mais letal, e qualquer tentativa de destoxificação da torta de mamona deve priorizar sua desativação (Anandan et al., 2005).

$\mathrm{Na}$ avaliação do valor nutricional das dietas, têm sido utilizada, além da composição bromatológica do alimento, o conhecimento da capacidade de utilização dos nutrientes pelo animal, o que pode ser obtido com estudos de digestibilidade e do consumo, que é um dos principais determinantes do processo produtivo. Diante do exposto, desenvolveu-se este trabalho com objetivo de avaliar o efeito de métodos alternativos de destoxificação da torta de mamona sobre o consumo e a digestibilidade dos nutrientes em ovinos alimentados com dietas contendo esse subproduto.

\section{MATERIAL E MÉTODOS}

Os tratamentos consistiram de quatro métodos distintos de destoxificação, além de mais um tratamento que representou a testemunha, no qual a torta de mamona não foi submetida a nenhum processo de destoxificação, sendo caracterizada como não tratada (NT). Dos métodos utilizados, três eram químicos e um físico, os quais foram: o uso do calcário calcítico (CC) na proporção de $60 \mathrm{~g} / \mathrm{kg}$ de torta de mamona, fosfato monobicálcico (FOS) na proporção de $60 \mathrm{~g} / \mathrm{kg}$ de torta de mamona, ureia (UR) na proporção de $10 \mathrm{~g} / \mathrm{kg}$ de torta de mamona e torta de mamona tratada com autoclave a 15 psi por 60 minutos (ACL).

Foi adotado o valor de $67 \%$ de substituição do farelo de soja pela torta de mamona para todos os tratamentos de acordo com Pompeu (2009), e o feno do capim-tifton 85 foi utilizado como volumoso. As rações experimentais foram formuladas com base nas recomendações do Nutrient... (2007), mantendo uma relação volumoso:concentrado de 50:50, sendo isoproteicas e isoenergéticas.

A torta de mamona foi obtida na miniusina de produção de biodiesel localizada na Fazenda Normal, em Quixeramobim-CE, a partir da extração mecânica (prensagem) do óleo da semente de mamona, utilizando temperaturas entre 90 e $100^{\circ} \mathrm{C}$. A composição percentual dos ingredientes e a composição química das dietas experimentais encontram-se nas Tab. 1 e 2, respectivamente.

$\mathrm{Na}$ avaliação do consumo e da digestibilidade dos nutrientes, foram utilizados vinte ovinos, em delineamento em blocos ao acaso, com cinco tratamentos e quatro repetições. Os blocos corresponderam ao sexo do animal (10 machos inteiros no bloco 1 e 10 fêmeas no bloco 2), que consistiram de ovinos ( $1 / 2$ Morada Nova $x$ 1/2 sem padrão racial definido) com peso vivo médio em torno de $19,8 \pm 1,18 \mathrm{~kg}$ e idade média de sete meses. Os animais foram alojados em gaiolas de metabolismo, providas de bebedouro, comedouro, equipadas com coletores e separadores de fezes e de urina. As dietas foram fornecidas diariamente à vontade, divididas em duas refeições iguais (às oito horas e às 16h), de modo a permitir sobras de $15 \%$ dos alimentos ofertados. 
Valor nutritivo de dietas...

Tabela 1. Composição percentual dos ingredientes nas dietas experimentais para ovinos, com base na matéria seca

\begin{tabular}{lccccc}
\hline \multirow{2}{*}{\multicolumn{1}{c}{ Ingrediente }} & \multicolumn{5}{c}{ Dieta contendo torta de mamona } \\
\cline { 2 - 6 } & NT & CC & UR & FOS & ACL \\
\hline Feno de capim-Tifton 85 & 49,83 & 49,89 & 49,91 & 49,99 & 49,86 \\
Fubá de milho & 34,06 & 34,23 & 34,03 & 33,96 & 34,01 \\
Farelo de trigo & 2,72 & 2,73 & 2,72 & 2,71 & 2,71 \\
Farelo de soja & 4,10 & 4,12 & 4,10 & 4,09 & 4,10 \\
Torta de mamona NT & 7,95 & - & - & - & - \\
Torta de mamona CC & - & 7,99 & - & - & - \\
Torta de mamona UR & - & - & 7,91 & - & - \\
Torta de mamona FOS & - & - & - & 7,87 & - \\
Torta de mamona ACL & - & - & - & - & 7,99 \\
Mistura mineral & 1,33 & 1,04 & 1,32 & 1,38 & 1,33 \\
\hline
\end{tabular}

NT: não tratada; CC: tratada com calcário calcítico; UR: tratada com ureia; FOS: tratada com fosfato monobicálcico; ACL: autoclavada.

Tabela 2. Composição química dos ingredientes e das dietas experimentais para ovinos

\begin{tabular}{|c|c|c|c|c|c|c|c|}
\hline \multirow{2}{*}{ Nutriente } & \multirow{2}{*}{$\begin{array}{l}\text { Torta de } \\
\text { mamona }\end{array}$} & \multirow{2}{*}{$\begin{array}{c}\text { Feno de } \\
\text { capim-tifton } 85\end{array}$} & \multicolumn{5}{|c|}{ Dietas contendo torta de mamona } \\
\hline & & & NT & $\mathrm{CC}$ & UR & FOS & ACL \\
\hline $\mathrm{MS}$ & 87,3 & 85,2 & 85,2 & 85,4 & 85,1 & 85,6 & 85,1 \\
\hline $\mathrm{MO}(\% \mathrm{MS})$ & 94,7 & 91,8 & 94,3 & 94,0 & 94,3 & 93,9 & 94,5 \\
\hline $\mathrm{PB}(\% \mathrm{MS})$ & 26,9 & 8,43 & 11,9 & 11,7 & 11,8 & 11,4 & 11,6 \\
\hline $\mathrm{EE}(\% \mathrm{MS})$ & 5,01 & 1,92 & 2,60 & 2,49 & 2,53 & 2,51 & 2,65 \\
\hline FDN (\% MS) & 49,8 & 74,65 & 47,1 & 46,2 & 46,7 & 46,7 & 47,0 \\
\hline FDA (\% MS) & 40,1 & 34,61 & 21,7 & 22,1 & 21,9 & 21,7 & 21,8 \\
\hline CUT (\% MS) & 25,7 & 0,87 & 2,01 & 1,72 & 2,81 & 1,68 & 2,06 \\
\hline $\mathrm{CT}(\% \mathrm{MS})$ & 62,8 & 81,5 & 79,8 & 79,8 & 79,9 & 80,0 & 80,2 \\
\hline $\mathrm{CNF}(\% \mathrm{MS})$ & 15,0 & 8,48 & 34,3 & 35,7 & 34,9 & 35,4 & 34,8 \\
\hline EB (Mcal/kg) & 4,59 & 3,77 & 3,88 & 3,87 & 3,81 & 3,81 & 3,88 \\
\hline NDT (\% MS) & 72,3 & 60,65 & 71,7 & 71,5 & 72,5 & 71,7 & 72,6 \\
\hline
\end{tabular}

NT: não tratada; CC: tratada com calcário calcítico; UR: tratada com ureia; FOS: tratada com fosfato monobicálcico; ACL: autoclavada; MS: matéria seca; MO: matéria orgânica; PB: proteína bruta; EE: extrato etéreo; FDN: fibra em detergente neutro; FDA: fibra em detergente ácido; CUT: cutina; CT: carboidratos totais; CNF: carboidratos não fibrosos; EB: energia bruta; NDT: nutrientes digestíveis totais.

O período experimental foi de 21 dias, sendo 14 dias para adaptação dos animais às dietas, às gaiolas de metabolismo e ao manejo e sete dias para mensuração do consumo voluntário de nutrientes e digestibilidade dos nutrientes. A determinação do consumo e da digestibilidade foi realizada por meio da pesagem e amostragem diárias durante o período de coleta do alimento oferecido, das sobras e das fezes de cada animal, que, em seguida, foram armazenadas em freezer a $-10^{\circ} \mathrm{C}$. Ao fim do período de coleta, as amostras foram descongeladas e homogeneizadas para confecção de amostras compostas por animal em cada tratamento, sendo retirada uma alíquota de aproximadamente $500 \mathrm{~g}$, pesada e pré-seca em estufa de ventilação forçada, a $55^{\circ} \mathrm{C}$ até peso constante, para determinação da matéria pré-seca. Foram, então, moídas em moinho de facas, com peneira de $1 \mathrm{~mm}$ e acondicionadas em recipientes plásticos para as análises posteriores.

As determinações de matéria seca (MS), matéria orgânica $(\mathrm{MO})$, matéria mineral $(\mathrm{MM})$, extrato etéreo (EE) e nitrogênio total foram realizadas de acordo com as técnicas descritas por Silva e Queiroz (2002), e a quantificação da fibra em detergente neutro (FDN), fibra em detergente ácido (FDA) seguiram os métodos de Van Soest et al. (1991). O teor de proteína bruta foi calculado multiplicando-se o teor de nitrogênio total de cada amostra por 6,25. Os carboidratos totais foram determinados pela seguinte fórmula: 
$\mathrm{CT}=100-(\% \mathrm{~PB}+\% \mathrm{EE}+\% \mathrm{MM})$ (Sniffen et al., 1992). Os carboidratos não fibrosos foram determinados de acordo com equação proposta por Hall (2000): $\mathrm{CNF}=100-[(\% \mathrm{~PB}-\% \mathrm{~PB}$ derivado da ureia $+\%$ da ureia) $+\%$ FDNcp + $\%$ EE + \% Cinzas], em que FDNcp equivale à parede celular corrigida para cinzas e proteínas.

O teor de nutrientes digestíveis totais (NDT) observado foi obtido a partir da equação: NDT = PBD + 2,25 $\times$ EED + FDNcpD + CNFD - 7, em que PBD, EED, FDNpD e CNFD significam, respectivamente, proteína bruta digestível, extrato etéreo digestível, fibra em detergente neutro (isenta de cinzas e proteína) digestível e carboidratos não fibrosos digestíveis (Weiss, 1999).

Com os valores obtidos nas análises da composição química das amostras, foram determinados os consumos de MS, MO, PB, EE, FDN, FDA, CT, CNF e NDT. O coeficiente de digestibilidade dos nutrientes foi determinado segundo a equação: digestibilidade (\%) = [nutriente ingerido $(\mathrm{g})$ - nutriente excretado nas fezes $(\mathrm{g})$ /nutriente ingerido $(\mathrm{g})] \times 100$.

Para a extração da ricina, $250 \mathrm{~g}$ de torta de cada tratamento foram diluídos em $1250 \mathrm{~mL}$ de água destilada e o pH foi ajustado a 3,8 com solução de ácido clorídrico a 1M (Anandan et al., 2005). Esse material permaneceu sobre agitação durante 17 horas, em seguida, foi filtrado, a parte retida no filtro foi diluída em $750 \mathrm{~mL}$ de água destilada e o pH foi novamente ajustado a 3,8 com solução de ácido clorídrico a 1M. Após três horas de agitação, esse material foi novamente filtrado, homogeneizado com o primeiro filtrado $\mathrm{e}$ liofilizado.

A corrida eletroforética foi realizada mediante géis de poliacrilamida com concentração de $5 \%$, em tampão Tris-HCl, pH 6,8 e com géis de separação com $15 \%$ de poliacrilamida em tampão Tris- $\mathrm{HCl} \mathrm{pH} 8,8$, contendo $0,1 \%$ de dodecil sulfato de sódio (SDS) a $10 \%$ (Laemmli e Favre 1973). As amostras liofilizadas $(4 \mathrm{mg} / \mathrm{mL})$ foram dissolvidas em tampão tris $\mathrm{HCl}$, $\mathrm{pH} 6,8$, na presença de $0,1 \%$ de SDS e $5 \%$ de $\beta$-mercaptoetanol. Em seguida, foram aquecidas a $100^{\circ} \mathrm{C}$ por três minutos e volume de $80 \mu \mathrm{L}$ foram depositados em cada poço do gel. A corrida eletroforética foi realizada a $4^{\circ} \mathrm{C}$ durante
$150 \mathrm{~min}$ com condições elétricas de $500 \mathrm{~V}, 60 \mathrm{~mA}$ e $30 \mathrm{~W}$.

Após o término da corrida, as proteínas foram coradas por 18 horas com $0,1 \% \quad(\mathrm{p} / \mathrm{v})$ de Coomassie Briliant Blue (R-250) dissolvidos em $50 \%(\mathrm{v} / \mathrm{v})$ de etanol e $1 \%$ de TCA. A descoloração foi realizada durante a noite com solução de $30 \%(\mathrm{v} / \mathrm{v})$ de etanol e $7,5 \%$ (v/v) de ácido acético. Posteriormente, o gel submetido a uma nova coloração por nitrato de prata, segundo protocolo adaptado de Blum et al. (1987), foi lavado três vezes com água destilada durante 20 minutos, seguindo-se a adição de thiosulfato de sódio $0,02 \%(\mathrm{p} / \mathrm{v})$, durante um minuto, e de nitrato de prata $0,1 \%(\mathrm{p} / \mathrm{v})$, por 30 minutos, sob agitação e ao abrigo da luz.

As proteínas foram reveladas utilizando-se uma solução de carbonato de cálcio $12 \%(\mathrm{p} / \mathrm{v}), 40 \mu \mathrm{L}$ de thiosulfato de sódio $2 \%(\mathrm{p} / \mathrm{v})$ e $200 \mu \mathrm{L}$ de formaldeído, sendo a reação finalizada com solução de ácido acético $1 \%(\mathrm{v} / \mathrm{v})$, quando foram fotografadas. $O$ padrão de pesos moleculares utilizado para identificação das proteínas foi o Bio-Rad, usando-se marcadores de massa molecular entre 200 e $6,5 \mathrm{kDa}$.

Os dados obtidos foram submetidos à análise de correlação de Pearson $(\mathrm{P}<0,05)$, à análise de variância e ao teste de comparação de médias, por meio do teste de Tukey em nível de 5\% de probabilidade. Como ferramenta de auxílio às analises estatísticas, utilizou-se o procedimento GLM do programa estatístico SAS.

\section{RESULTADOS E DISCUSSÃO}

O efeito dos tratamentos aos quais foi submetida a torta de mamona caracterizou-se pela separação da ricina em duas subunidades e pela mudança de intensidade na coloração dessas subunidades. Nesse sentido, observou-se que em nenhum dos tratamentos testados (calcário calcítico, ureia, fosfato monobicálcico e autoclave) ocorreu o completo desaparecimento das subunidades de ricina. Entretanto, percebeu-se redução substancial na intensidade das subunidades de ricina no tratamento que recebeu torta de mamona tratada com fosfato monobicálcico. Essa redução está associada ao pH de 4,08 do fosfato monobicálcico em solução na época da realização do tratamento da torta de mamona, podendo esse $\mathrm{pH}$ ácido ter concorrido para a desnaturação parcial da ricina (Fig. 1). 


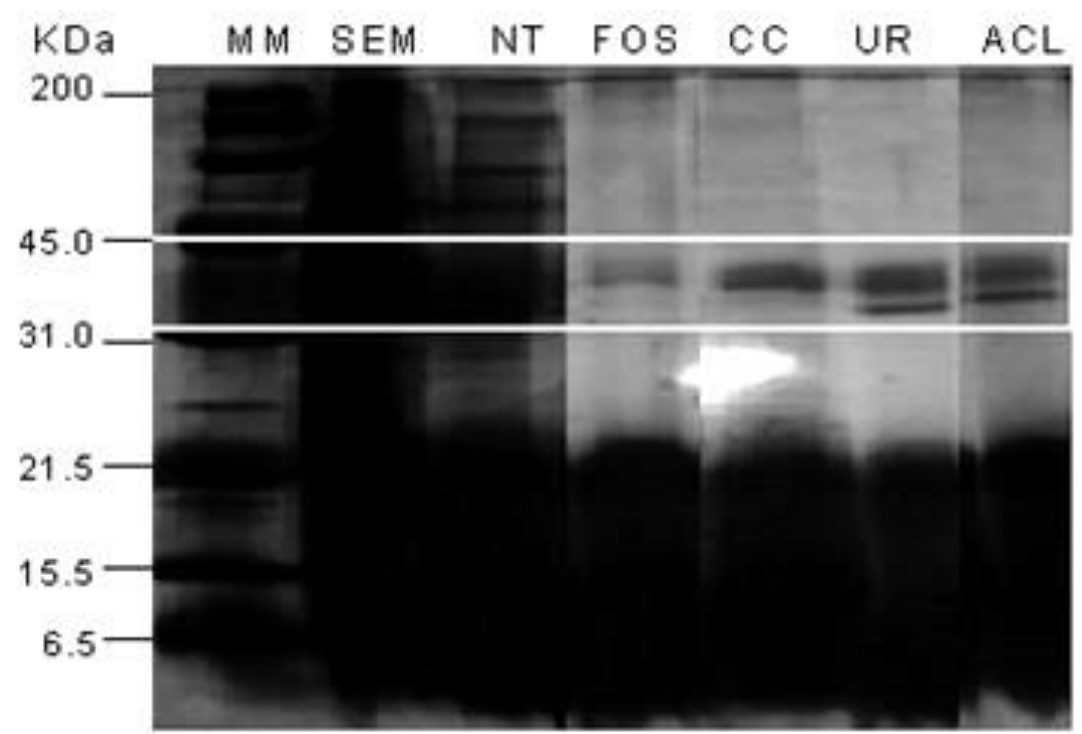

Figura 1. Eficácia dos tratamentos da torta de mamona no desaparecimento das duas subunidades de ricina (A com 35KDa e B com 29KDa). $\mathrm{MM}=$ marcador de massa molecular (6,5 a 200KDa); SEM = sementes de mamona; NT= torta de mamona não tratada; $F O S=$ torta de mamona tratada com fosfato monobicálcico; $\mathrm{CC}=$ torta de mamona tratada com calcário calcítico; $\mathrm{UR}=$ torta de mamona tratada com ureia; $\mathrm{ACL}=$ torta de mamona tratada por autoclave.

O uso da autoclave (15psi/60min.) não destoxificou completamente a torta de mamona, resultado esse diferente do observado por Anandan et al. (2005), que, ao testarem diferentes métodos químicos e físicos de destoxificação da ricina, obtiveram eficiência de $100 \%$ de destoxificação da ricina ao utilizar autoclave a 15psi por 60 minutos ou hidróxido de cálcio $(40 \mathrm{~g} / \mathrm{kg}$ de farelo de mamona). Possivelmente, a diferença na eficácia do processo deveu-se a diferenças no teor de ricina entre os materiais genéticos. Esses autores relataram teor de ricina de $388 \mathrm{mg} / \mathrm{kg}$ de farelo de mamona, ao passo que Oliveira et al. (2010), destoxificando material genético brasileiro por meio do hidróxido de cálcio $\left(\mathrm{CaOH}_{2}\right)$, também não conseguiram destoxificar em $100 \%$ a torta de mamona ao utilizar $40 \mathrm{~g}$ de $\mathrm{CaOH}_{2}$ por $\mathrm{kg}$ de torta de mamona, obtendo uma eficiência de $64,8 \%$, o que foi atribuído ao elevado teor de ricina presente na torta de mamona utilizada $(799 \mathrm{mg} / \mathrm{kg}$ de torta de mamona).

Não foi verificado efeito $(\mathrm{P}>0,05)$ dos métodos alternativos de destoxificação da torta de mamona sobre o consumo de matéria seca (CMS), matéria orgânica (CMO), proteína bruta (CPB), extrato etéreo (CEE), fibra em detergente neutro (CFDN), fibra em detergente ácido
(CFDA), carboidratos totais (CCT), carboidratos não fibrosos (CCNF) e nutrientes digestíveis totais (CNDT) em nenhuma das unidades analisadas (g/dia, \%PV), conforme observado na Tab. 3.

O CMS de todas as rações testadas, quando expresso em g/dia e \%PV, foi superior $(\mathrm{P}<0,05)$ aos $760 \mathrm{~g} / \mathrm{dia}$ e $3,8 \%$ do $\mathrm{PV}$ recomendados pelo Nutrient... (2007) para ovinos de $20 \mathrm{~kg}$ de peso vivo em fase de crescimento e maturidade tardia, o que preconiza ganhos de até $150 \mathrm{~g} /$ dia. Também não foi observada diferença $(\mathrm{P}>0,05)$ entre as dietas experimentais para o CMO, apesar de, nas rações contendo torta de mamona tratada com calcário calcítico ou com fosfato monobicálcico, terem sido adicionados $60 \mathrm{~g}$ de cada um desses ingredientes, demonstrando não serem suficientes para alterar significativamente o teor de matéria orgânica das dietas experimentais.

A semelhança $(\mathrm{P}>0,05)$ no $\mathrm{CPB}$ está relacionada ao fato de que as dietas eram isoproteicas (Tab. 2); além disso, o CMS também não diferiu $(\mathrm{P}>0,05)$ entre as dietas, e foi observada alta correlação entre o CMS e o CPB ( $\mathrm{r}=0,9789 * *)$. Os dados obtidos foram mais baixos que os de Pompeu (2009), que, ao estudar a influência de quatro níveis de substituição do farelo de soja 
pela torta de mamona destoxificada em dietas para ovinos, observou CPB de 134,9g/dia e $119,2 \mathrm{~g} /$ dia nos níveis de substituição de $67 \mathrm{e}$ $100 \%$, respectivamente. Isso pode ser atribuído, em parte, ao maior peso dos animais utilizados pelo autor e ao maior tempo de permanência destes animais alimentando-se das dietas durante o ensaio de desempenho.

Tabela 3. Médias do consumo de nutrientes, efeito de sexo e coeficiente de variação (CV) em ovinos alimentados com dietas contendo torta de mamona submetida a métodos alternativos de destoxificação

\begin{tabular}{|c|c|c|c|c|c|c|c|c|}
\hline \multirow{2}{*}{ Variável } & \multicolumn{5}{|c|}{ Dietas contendo torta de mamona } & \multicolumn{2}{|c|}{ Sexo } & \multirow{2}{*}{$\begin{array}{l}\mathrm{CV} \\
(\%)\end{array}$} \\
\hline & NT & $\mathrm{CC}$ & UR & FOS & ACL & Macho & Fêmea & \\
\hline \multicolumn{9}{|c|}{ Consumo em g/dia } \\
\hline CMS & 787,0 & 839,5 & 763,5 & 836,0 & 837,7 & 863,9 & 761,2 & 13,87 \\
\hline $\mathrm{CMO}$ & 743,5 & 789,0 & 721,4 & 787,8 & 791,9 & 815,2 & 718,2 & 13,82 \\
\hline $\mathrm{CPB}$ & 95,4 & 103,6 & 94,4 & 98,7 & 102,2 & 104,3 & 93,4 & 13,99 \\
\hline CEE & 21,3 & 22,3 & 20,4 & 22,2 & 24,1 & 23,2 & 20,9 & 13,23 \\
\hline CFDN & 363,4 & 358,1 & 335,8 & 370,6 & 368,4 & $385,3 \mathrm{~A}$ & $333,2 \mathrm{~B}$ & 14,55 \\
\hline CFDA & 164,3 & 168,8 & 154,3 & 168,6 & 168,0 & $176,5 \mathrm{~A}$ & $153,1 \mathrm{~B}$ & 15,10 \\
\hline $\mathrm{CCT}$ & 626,9 & 663,2 & 606,6 & 667,0 & 665,6 & 687,8 & 603,9 & 13,86 \\
\hline CCNF & 275,5 & 324,0 & 284,0 & 313,9 & 310,9 & 318,5 & 284,8 & 14,36 \\
\hline CNDT & 524,8 & 557,7 & 514,4 & 554,8 & 555,5 & 573,8 & 509,1 & 12,89 \\
\hline \multicolumn{9}{|c|}{ Consumo em \%PV } \\
\hline CMS & 4,21 & 4,40 & 4,23 & 4,34 & 4,45 & 4,52 & 4,14 & 10,19 \\
\hline CFDN & 1,94 & 1,88 & 1,87 & 1,93 & 1,96 & 2,02 & 1,81 & 11,83 \\
\hline
\end{tabular}

CMS: consumo de matéria seca; CMO: consumo de matéria orgânica; CPB: consumo de proteína bruta; CEE: consumo de extrato etéreo; CFDN: consumo de fibra em detergente neutro; CFDA: consumo de fibra em detergente ácido; CCT: consumo de carboidratos totais; CCNF: consumo de carboidratos não fibrosos; CNDT: consumo de nutrientes digestíveis totais. NT: não tratada; CC: tratada com calcário calcítico; UR: tratada com ureia; FOS: tratada com fosfato monobicálcico; ACL: autoclavada.

A ausência de efeito $(\mathrm{P}>0,05)$ dos métodos alternativos de destoxificação da torta de mamona sobre o CEE pode ser atribuída ao fato de que os tratamentos de destoxificação da torta de mamona não alteraram substancialmente o teor de extrato etéreo das dietas experimentais. $\mathrm{O}$ elevado teor de extrato etéreo (EE) presente na torta de mamona pode ser um fator prejudicial no consumo de matéria seca pelos animais, entretanto, no presente estudo, o teor de EE das dietas com inclusão de torta de mamona esteve abaixo dos $6 \%$ na dieta total. Portanto, não houve efeito negativo sobre o consumo de nutrientes, seja por mecanismos regulatórios que controlam o consumo de alimentos, ou pela capacidade limitada dos ruminantes de oxidar os ácidos graxos ou até mesmo o efeito físico pelo recobrimento das partículas alimentares com gordura, com consequente redução do contato destas com agentes de digestão (Palmquist e Mattos, 2006).

O CFDN médio observado foi de $359,25 \mathrm{~g} / \mathrm{dia}$ ou $1,91 \%$ PV, bem acima de 1,2\% sugerido por Mertens (1994) como sendo o valor a partir do qual o consumo será limitado pelo enchimento físico do rúmen, e abaixo deste, quando o consumo será limitado pela densidade energética da dieta. $\mathrm{O}$ autor comentou que esse limite pode ser ultrapassado por animais alimentados com rações contendo baixa densidade energética, na tentativa de compensar a limitação energética da dieta. Pompeu (2009), trabalhando com ovinos deslanados alimentados com dietas contendo teor de FDN de aproximadamente 52\%, obteve 
consumo médio de FDN superior a 1,7\% PV, semelhante ao registrado nesta pesquisa.

Todas as dietas satisfizeram as necessidades dos animais em NDT, obtendo CNDT médio de $541,45 \mathrm{~g} /$ dia, estando acima do consumo diário de NDT de $500 \mathrm{~g} /$ dia preconizado pelo Nutrient... (2007) para essa categoria de animais.

Quanto ao efeito de sexo, não foi verificado efeito entre machos e fêmeas para o CMS, CMO, CPB, CEE, CCT, CCNF e CNDT. Foi observado maior CFDN e CFDA pelos machos quando expressos em g/dia, podendo ser explicados pela maior capacidade ruminal ao longo do desenvolvimento corporal, uma vez que a capacidade física de enchimento do rúmen apresenta relação direta com o tamanho do animal. Isso significa que, à medida que o animal aumenta de tamanho, o tamanho do rúmen aumenta na mesma proporção (Van Soest, 1994), o que permitiu, nesta pesquisa, maior consumo da fração fibrosa do alimento pelos machos.
Gomes (2010), ao trabalhar com os mesmos animais desta pesquisa e avaliar as medidas corporais, as características da carcaça e os componentes não carcaça após um ensaio de desempenho, verificou valores mais altos de rúmen-retículo dos machos $(0,663 \mathrm{~kg})$ em relação às fêmeas $(0,552 \mathrm{~kg})$.

Os coeficientes de digestibilidade da MS, MO, PB, FDA, CT, CNF e NDT variaram pouco entre os tratamentos (Tab. 4), não apresentando diferenças entre si $(\mathrm{P}>0,05)$. Estes resultados assemelharam-se aos obtidos por Diniz et al. (2011), que, ao estudarem níveis crescentes de substituição do farelo de soja por torta de mamona tratada com $60 \mathrm{~g}$ de óxido de cálcio em dietas para bovinos, encontraram valores médios de 70,9;70,82; 62,15 e 65,6 para DMS, DMO, DPB e NDT, respectivamente. Oliveira et al. (2010) também não observaram efeito do tratamento do farelo e da torta de mamona com hidróxido de cálcio sobre os coeficientes de digestibilidade dos nutrientes.

Tabela 4. Médias dos coeficientes de digestibilidade in vivo em ovinos alimentados com dietas contendo torta de mamona submetida a diferentes métodos de destoxificação

\begin{tabular}{|c|c|c|c|c|c|c|c|c|}
\hline \multirow{2}{*}{ Variável } & \multicolumn{5}{|c|}{ Dietas contendo torta de mamona } & \multicolumn{2}{|c|}{ Sexo } & \multirow{2}{*}{$\begin{array}{l}\mathrm{CV} \\
(\%)\end{array}$} \\
\hline & NT & $\mathrm{CC}$ & UR & FOS & $\mathrm{ACL}$ & Macho & Fêmea & \\
\hline CDMS & 67,58 & 67,28 & 67,75 & 66,75 & 66,33 & 66,88 & 67,39 & 3,22 \\
\hline CDMO & 68,44 & 68,26 & 68,91 & 68,11 & 67,42 & 67,94 & 68,51 & 3,14 \\
\hline CDPB & 67,09 & 68,69 & 67,33 & 65,57 & 66,02 & 66,53 & 67,34 & 3,81 \\
\hline CDEE & $70,12 \mathrm{ab}$ & $71,29 \mathrm{a}$ & $69,17 \mathrm{ab}$ & $68,22 b$ & $70,42 \mathrm{ab}$ & 69,13 & 70,56 & 2,72 \\
\hline CDFDN & $57,52 \mathrm{a}$ & $52,42 \mathrm{~b}$ & $56,08 \mathrm{ab}$ & $55,07 \mathrm{ab}$ & $54,89 \mathrm{ab}$ & 55,16 & 55,23 & 5,23 \\
\hline CDFDA & 48,47 & 44,94 & 46,80 & 46,67 & 47,01 & 46,18 & 47,38 & 8,27 \\
\hline CDCT & 68,59 & 68,09 & 69,14 & 68,49 & 67,52 & 68,11 & 68,62 & 3,21 \\
\hline CDCNF & 81,93 & 84,65 & 83,20 & 83,36 & 81,04 & 82,64 & 83,03 & 3,78 \\
\hline NDT & 67,02 & 66,55 & 67,42 & 66,45 & 66,35 & 66,44 & 67,08 & 3,09 \\
\hline
\end{tabular}

CDMS: coeficiente de digestibilidade da matéria seca; CDMO: coeficiente de digestibilidade da matéria orgânica; CDPB: coeficiente de digestibilidade da proteína bruta; CDEE: coeficiente de digestibilidade do extrato etéreo; CDFDN: coeficiente de digestibilidade da fibra em detergente neutro; CDFDA: coeficiente de digestibilidade da fibra em detergente ácido; CDCT: coeficiente de digestibilidade dos carboidratos totais; CDCNF: coeficiente de digestibilidade dos carboidratos não fibrosos; NDT: nutrientes digestíveis totais; NT: não tratada; CC: tratada com calcário calcítico; UR: tratada com ureia; FOS: tratada com fosfato monobicálcico; ACL: autoclavada.

O CDEE foi melhor $(\mathrm{P}<0,05)$ na dieta $\mathrm{CC}$ em relação à FOS, entretanto esta variação foi pouco relevante, uma vez que representa um aumento de apenas 4,5\% no coeficiente de digestibilidade.
Já para o CDFDN, verificou-se superioridade na dieta NT em relação à dieta $\mathrm{CC}$, correspondendo a uma variação de $9,7 \%$ na digestibilidade. De forma semelhante, Oliveira et al. (2010) 
observaram alterações na DEE em dietas contendo torta ou farelo de mamona submetidos a tratamento químico $\left(\mathrm{CaOH}_{2}\right)$ de destoxificação, obtendo valores de DEE superiores para as dietas que continham farelo ou torta de mamona tratados com hidróxido de cálcio $\left(\mathrm{CaOH}_{2}\right)$ em relação às dietas que receberam farelo ou torta de mamona sem tratamento de destoxificação.

Não foi observado efeito de sexo sobre coeficientes de digestibilidade de todos os nutrientes.

\section{CONCLUSÕES}

A utilização de $60 \mathrm{~g}$ de calcário calcítico, $10 \mathrm{~g}$ de ureia, $60 \mathrm{~g}$ de fosfato monobicálcico e autoclave a $15 \mathrm{psi} / 60$ minutos, por não promover o completo desaparecimento da ricina presente na torta de mamona, não ocasiona grandes melhoras no consumo e na digestibilidade dos nutrientes. A torta de mamona sem tratamento de destoxificação pode ser utilizada nas dietas de ovinos como alimento proteico alternativo, participando em até $8 \%$ da ração total, sem ocasionar expressivas reduções no consumo e na digestibilidade.

\section{REFERÊNCIAS}

ANANDAN, S; ANIL KUMAR, G.K.; GHOSH, J. et al. Effect of different physical and chemical treatments on detoxification of ricin in castor cake. Anim. Feed Sci. Technol., v.120, p.159-168, 2005.

BLUM, H.; BEIER, H.; GROSS, H.J. Improved silver staining of plant proteins, RNA and DNA in polyacrilamide gels. Electrophoresis, v.8, p.93-95, 1987.

CARVALHO JUNIOR, J.N.; PIRES, A.J.V.; VELOSO, C.M. et al. Digestibilidade aparente da dieta com capim-elefante ensilado com diferentes aditivos. Arq. Bras. Med. Vet. Zootec., v.62, p.889897,2010

DINIZ, L. L.; VALADARES FILHO, S. C.; OLIVEIRA, A. S. et al. Castor bean meal for cattle finishing: nutritional parameters. Livest. Sci., v.135, p.153-167, 2011.

GOMES, F.H.T. Consumo, comportamento ingestivo e desempenho bioeconômico de ovinos alimentados com rações contendo torta de mamona. 2010. 123f. Dissertação (Mestrado) - Universidade Federal do Ceará, Fortaleza, CE.
HALL, M.B. Calculation of non-structural carbohydrate content of feeds that contain non-protein nitrogen. Florida: University of Florida, 2000. (Bulletin 339).

LAEMMLI, U.K.; FAVRE, M. Maturation of the head of bacteriophage T4. J. Mol. Biol., v. 80, p. 575-599, 1973

MERTENS, D.R. Regulation of forage intake. In: FAHEY JR., G.C. (Ed.) Forage quality, evaluation and utilization. Madison: American Society of Agronomy, 1994. p.450-493.

NUTRIENT requirements of small ruminants: sheep, goats, cervids, and new world camelids. Washington: National Academy, 2007. 362 p.

OLIVEIRA, A.S.; CAMPOS, J.M.S.; OLIVEIRA, M.R.C. et al. Nutrient digestibility, nitrogen metabolism and hepatic function of sheep fed diets containing solvent or expeller castor seed meal treated with calcium hydroxide. Anim. Feed Sci. Technol., v. 158, p.15-28, 2010

PALMQUIST, D.L.; MATTOS, W.R.S. Metabolismo de lipídeos. In: BERCHIELLI, T.T.; PIRES, A.V.; OLIVEIRA, S. G. Nutrição de ruminantes. Jaboticabal: FUNEP, 2006. p.287-310.

POMPEU, R.C.F.F. Substituição do farelo de soja pela torta de mamona destoxificada em dietas para ovinos: valor nutritivo e desempenho bioeconômico. 2009. 101f. Tese (Doutorado) - Universidade Federal do Ceará, Fortaleza, CE.

SILVA, D.J.; QUEIROZ, A.C. Análise de alimentos: métodos químicos e biológicos. 3.ed. Viçosa: UFV, 2002. $165 \mathrm{p}$

SNIFFEN, C.J.; O'CONNOR, D.J.; VAN SOEST, P.J. et al. A net carbohydrate and protein system for evaluating cattle diets: carbohydrate and protein availability. J. Anim. Sci., v.70, p.3562-3577, 1992.

VAN SOEST, P.J. Nutritional ecology of the ruminant. 2.ed. Ithaca: Cornell University. 1994. $476 \mathrm{p}$.

VAN SOEST, P.J.; ROBERTSON, J.B.; LEWIS, B.A. Methods for dietary fiber, and nonstarch polysaccharides in relation to animal nutrition. $J$. Dairy Sci., v.74, p.3583-3597, 1991.

WEISS, W.P. Energy prediction equations for ruminant feeds. In: CORNELL NUTRITION CONFERENCE FOR FEED MANUFACTURERS, 61., 1999, Ithaca. Proceedings... Ithaca: Cornell University, 1999. p.176-185. 